\title{
SPONTANEOUS SUBLINGUAL HEMATOMA; A RARE EMERGENCY
}

\author{
Kamran Zamurrad Malik, Ameer Abdullah*, Tarique Ahmed Maka** \\ Combined Military Hospital Nowshera/National University of Medical Sciences (NUMS) Pakistan, *Combined Military Hospital Kharian/National University of \\ Medical Sciences (NUMS) Pakistan, ${ }^{* *}$ Combined Military Hospital Risalpur/National University of Medical Sciences (NUMS) Pakistan
}

\section{ABSTRACT}

Sublingual hematoma or pseudo-Ludwig's phenomenon, is a rare entity seen in anticoagulated patients and can precipitate upper airway obstruction. We present a case of sublingual haematoma with huge swelling in the floor of mouth that impending airway compromise in a mitral valve replaced patient with ominously deranged coagulation profile. Multiple cases reported in the literature of spontaneous sub-mental hematoma with varying management plans, including: conservative management with close observation in IMCU/ICU, prophylactically securing the airways with elective intubation and/or emergency tracheostomy. Some authors proposed an evacuation the hematoma through an incision along the floor of the mouth. This case was kept under intensive care with strict vitals and airway monitoring and managed conservatively.

Keywords: Pseudo-Ludwig's angina, Sublingual hematoma, Warfarin.

This is an Open Access article distributed under the terms of the Creative Commons Attribution License (https://creativecommons.org/licenses/by-nc/4.0/), which permits unrestricted use, distribution, and reproduction in any medium, provided the original work is properly cited.

\section{INTRODUCTION}

Submental hematoma also known as pseudo-ludwig's angina, an exceptional medical case, resulting from spontaneous hematoma in the sublingual space that may lead to airway obstruction. The floor of the oral cavity, being highly vascular, is infrequently a spot of hematoma development. Although very rare, hematomas formation in the base of oral cavity have been defined after trauma, dental implant processes, uncontrolled hypertension and angioedema. This disorder is frequently seen in those patients who are on anticoagulants with obviously coagulation profile deranged. It issupposed to be secondary toaneurysmal changes in facial or lingual arteries. The hematomas in sublingual region are potentially fatal as these causes welling in the floor of mouth and elevation of tongue leading to airway obstruction. The most common complication of spontaneous submental hematoma is upper airway obstruction and it need sexigent intervention for conservation of the airway. In the literature reported with previous cases there is no definitive consensus on the management of these patients. The foremost step in management of this condition is to protect the airway.

We present a case of sublingual haematoma with huge swelling in the floor of mouth that impedes airway conciliation in a mitral valve replaced patient with ominously deranged coagulation profile.

\section{CASE REPORT}

\section{A 54-year-old female patient reported in}

Correspondence: Dr Tarique Ahmed Maka, Classified ENT Specialist, Combined Military Hospital Risalpur Pakistan

Received: 10 Aug 2019; revised received: 12 Oct 2020; accepted: 01 Apr 2020 emergency department with the chief complaint of pain \& swelling below her tongue for last 3 days. Swelling started 3 days ago and was rapidly progressing. It was accompanied by sense of heaviness which transformed into acute pain with increase in size of swelling. She had difficulty in swallowing and voice was muffled. There was no history of fever, trauma, or fluctuation in the size of swelling. The patient had mitral valve replacement two years ago and was on oral anticoagulation therapy (warfarin). She did not had her coagulation profile done for last 6-8 months. She was normoglycemic and normotensive.

Examination revealed a well oriented, conscious but anxious lady with stable vital signs. There was a soft but tense reddish swelling in her floor of mouth, lifting tongue upwards. The swelling was non pulsatile, non-tender, non-fluctuant, without raised temperature and with scant hemorrhagic drops along the margins. She was not striderolous without any breathing difficulty. Also, there were no intraoral lacerations or abrasions. Her systematic examination was normal. She was hospitalized with the diagnosis of spontaneous sublingual hematoma due to warfarin induced coagulopathy and kept in intensive care to monitor her respiration and rest of vitals. She was started with inj vitamin $\mathrm{K}$ and Co-amoxiclav. Her blood complete picture, LFT, RFT, sugar, Urine RE were normal but her blood failed to clot on coagulation studies. She was transfused six units of fresh frozen plasma. Her swelling increased in size following day with elevation of tongue but respiration remained satisfactory. Prothrombin time started to improve and her INR was 1:1 on fourth day. From third day onwards the swelling started to settle and floor of mouth was nearly flat on 
eighth day.

She was discharged from ENT side and was being followed up in cardiac surgery dept. she was symptom free and was on strict coagulation monitoring.

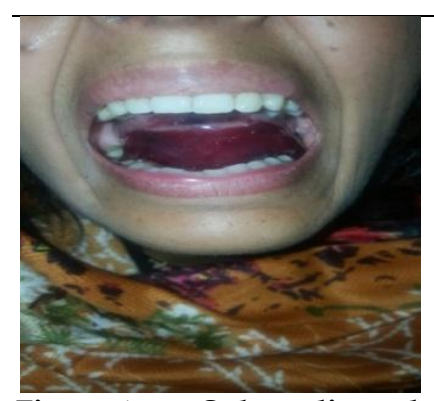

Figure-1: Sub lingual hematoma.

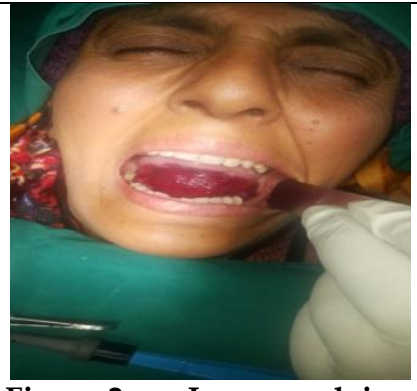
phase.
Figure-2: In resolving

\section{DISCUSSION}

Submental hematoma is a very rare clinical phenomenon instigated by deranged coagulation profile that may lead to spontaneous bleeding into the sublingual space and may lead to upper airway obstruction $^{1}$. The base of oral cavity is consisted of loose soft tissue with numerous potential fascial spaces and is enclosed by a thin layer of mucosa. These spaces can be pooled by blood and expand rapidly. This pooled blood along with local edema causing tongue displaced posteriorly and precipitated to airway obstruction ${ }^{2}$.

Spontaneous hematoma also known as "PseudoLudwig's" phenomenon, which was first described by Lepore in 1976 as a disorder instigated by deranged hemostasis with anticoagulation (warfarin) treatment ${ }^{3}$.

The differential diagnosis for spontaneous hematoma included trauma, dental procedure, uncontrolled hypertension, AVM, pseudoaneurysm, or angioedema. The swelling in these cases started rapidly and bilaterally, which is an unanticipated location for trauma ${ }^{4,5}$.

Angioedema is a swift engorgement of the submucosal, subcutaneous and dermal tissues frequently complemented with pain, urticarial and pruritus, generally caused by anallergen or angiotensin-converting enzyme (ACE) inhibitor. CT neck angiogram showed no any anomalous arteriovenous malformation (AVM) and pseudo-aneurysm ${ }^{6}$.

In our case of sublingual hematoma the etiology was deranged coagulation with warfarin. In every case of sublingual haematoma detailed history and completephysical examination must be done specially drug history about anti-coagulation therapy is essential. The diagnosis is basically clinical so the clinicians need to investigate all the coagulation related blood tests and accomplish it consequently?.

In the previous reports, there is no conclusive harmony in the managing of these patients. The foremost managing urgency is to see and secure patient's upper respiratory tract. Patient can be intubated by oral or nasal tube, if it is impossible or difficult due to progressive swelling or size of haematoma emergency tracheostomy may be indicated. However conservative management of these cases comprises of correction of anticoagulation therapy is mostly successful with or without surgical drainage ${ }^{8}$.

Surgical intervention of sublingual hematoma is still controversial in the literature. Most of cases were managed conservatively resulting in subsiding the size of swelling as soon as the contributing aspects have been controlled. Even though in sublingual hematoma due to deranged coagulopathy, once the coagulation profile return to normal the swelling has been resolved spontaneously without surgical intervention. Some of the clinicians avoid surgical intervention to evacuate the blood that can aggravate the size of swelling and consequent worsening of condition in postoperative period. In literature leeches have also been used to suck the blood and aid in the resolution of sublingual hematoma, but there is psychological burden on the patient and the risk of anaerobic infection must be considered ${ }^{9,10 .}$.

This case was kept under intensive care with strict vitals and airway monitoring and managed conservatively, although the swelling deteriorated initially but the conservative management proved to be successful. The airway must be protected when feasible and decide immediately the surgical intervention when required.

\section{CONCLUSION}

Spontaneous sublingual haematoma is a rare but urgent condition in the oral cavity. There is no consensus on the clinical strategies and management of these patients. The top priority of a clinician's strategy is to protect the airway. Based on the cases previously reported in the literature and our clinical experience, we considered conservative management as more beneficial and safe. Surgical intervention is controversial, having multiple complications and be serious to the patient.

\section{CONFLICT OF INTEREST}

This study has no conflict of interest to be declared by any author. 


\section{REFERENCES}

1. Zacharia GS, Kandiyil S, Thomas V. Pseudo-Ludwig's Phenomenon: A Rare Clinical Manifestation in Liver Cirrhosis.. ACG Case Rep J 2014; 2(1): 53-54.

2. Cohen AF, Warman SP. Upper airway obstruction secondary to warfarin-induced sublingual hematoma. Arch Otolaryngol Head Neck Surg 1989; 115(6): 718-20.

3. Lovallo E, Patterson S, Erickson M, Chin C, Blanc P, Durrani TS. When Is "Pseudo-Ludwig's Angina" Associated With Coagulopathy Also a "Pseudo" Hemorrhage? J Investig Med High Impact Case Rep 2013; 1(2): 1-5.

4. Alamoudi U, Alsallumi Y, Rigby MH, Taylor SM, Trites JRB, Hart RD. Spontaneous submental hematoma, a pseudo-Ludwig's phenomenon in 101-year-old patient: case report and literature review. Int J Surg Case Rep 2017; 36(1): 98-102.

5. Pathak R, Supplee S, Aryal MR, Karmacharya P. Warfarin indu- ced sublingual hematoma: A Ludwig angina mimic. Am J Otolaryngol 2015; 36(1): 84-86.

6. Cashman E, Shandilya M, Amin M, Hughes J, Walsh M. Warfarin-induced sublingual hematoma mimicking Ludwig angina: Conservative management of a potentially life-threatening condition. Ear Nose Throat J 2011; 90(2): E1.

7. Gupta MK, McClymont LG. Case of sublingual hematoma threatening airway obstruction. Med Sci Monit 2003; 9(11): CS95-97.

8. Buyuklu M, Bakirci EM, Topal E, Ceyhun G. Spontaneous lingual and sublingual haematoma: a rare complication of warfarin use. BMJ Case Rep 2014; 2014: 1-3.

9. Pathak R, Supplee S, Aryal MR, Karmacharya P. Warfarin induced sublingual hematoma: a Ludwig angina mimic. Am J Otolaryngol 2015; 36(1): 84-86.

10. Evgeni B, Leonid K, Schwartz A, Efim R, Amit F, Alexander Z, et al. Spontaneous sublingual hematoma: Surgical or non-surgical management? Intl J Case Rep Imag 2012; 3(1): 1-4. 